\title{
Advancement in Molecular Hydrogen Storage Systems
}

\author{
Sebastian Sahler and Martin H. G. Precht|*[a] \\ Dedicated to Professor Erhard Kemnitz on the occasion of his $60^{\text {th }}$ birthday
}

The increasing shortage of fossil hydrocarbons as energy carriers forecast for the $21^{\text {st }}$ century leaves an important challenge for chemists all over the world. To ensure individual mobility, an effectively transportable energy-carrying medium has to be found. As one adequate material, dihydrogen has often been discussed. ${ }^{[1,2]}$ The challenges of storage and transportation are based on the low volumetric density of gaseous hydrogen and the disadvantages of the more dense forms of gaseous or liquid hydrogen: Both possibilities are a source of danger in case of accidents and the effort to pressurize or liquefy dihydrogen is quite high. These topics are discussed elsewhere in more detail. ${ }^{[1,3]}$ One promising attempt to overcome these obstacles is the employment of molecular ammonia borane derived systems that are capable of chemically storing hydrogen under near-ambient conditions, likewise formic acid based systems. ${ }^{[4]}$ The application of ammonia borane (AB) itself entails problems with the associated solid waste products: Handling and ease of regeneration are limited. The fact that there is already a worldwide infrastructure to handle liquid fuels makes the effort to find an efficient liquid hydrogen storage material worthwhile. Regarding these facts, ionic liquids (IL) are promising, owing to their tunable physicochemical properties. ${ }^{[5]}$ Recent advances in dehydrogenation of ammonia borane derived systems are highlighted here. Current research focuses on hydrogen-enriched light material blends, ${ }^{[6-8]}$ and catalytic decomposition. ${ }^{[9,10]}$ Furthermore ILs are interesting for their supporting activity in decomposition, ${ }^{[11]}$ and ability to solute a wide range of materials including spent fuel by-products. ${ }^{[10]}$ Lately the above mentioned approaches are in some extent combined. ${ }^{[10]}$

In recent work Lentz and co-workers studied a molecule derived from $A B$, namely hydrazine borane $(\mathrm{HzB})$ and its decomposition characteristics. ${ }^{[7]}$ Although $\mathrm{HzB}$ is able to release hydrogen by itself, the efficiency of release was improved by combining $\mathrm{HzB}$ with a hydride-donor ( $\mathrm{HzB}$ contains 4 acidic, but only 3 hydridic hydrogen atoms), namely LiH: The 1:1 mixture is theoretically able to release $14.8 \mathrm{wt} \%$ of hydrogen and nearly $12 \mathrm{wt} \%$ could be realized at $150^{\circ} \mathrm{C}$ in $4.5 \mathrm{~h}$. Despite these promising results Lentz and co-workers faced the problems accompanying solid, insoluble, undefined products as a major hindrance for an efficient regeneration process.

[a] S. Sahler, Dr. M. H. G. Prechtl

Department Chemie_-Institut für Anorganische Chemie

Greinstr. 6, 50939 Köln (Germany)

Fax: (+ 49) 221-470-1788

E-mail:martin.prechtl@uni-koeln.de

Homepage: http://catalysis.uni-koeln.de
The employment of guanidinium borohydride salt (GBH) as an alternative hydrogen storage material has been investigated by Groshens and co-workers with remarkable results (Figure 1). ${ }^{[6]}$ The guanidinium ion contributes acidic protons,

$$
{ }_{\mathrm{GBH}}^{\mathrm{H}_{2} \mathrm{~N}_{+}+\mathrm{NH}_{2}}
$$

Figure 1. Structures of GBH and EDB.

whereas the borohydride adds the demanded hydridic part. As this acid-base pair consists only of the required hydrogen and atoms of the light elements boron, nitrogen, and carbon, it represents a dihydrogen source of notable weight efficiency, theoretically able to release up to $10.8 \mathrm{wt} \%$. In further investigations, results showed that the addition of ethylenediamine bisborane (EDB) maintains almost unchanged (weight-) efficiency, while significantly inhibiting the production of ammonia as the major impurity (Figure 1). Different molar ratios of GBH and EDB have been investigated at temperatures as low as $60^{\circ} \mathrm{C}$. Pure $\mathrm{GBH}$ decomposed with an impurity of ammonia of $4.1 \mathrm{~mol} \%$, while the total dihydrogen yield was $10.6 \mathrm{wt} \%$. In comparison a 40:60 wt \% mixture of GBH and EDB decreased the impurity of ammonia to $0.026 \mathrm{~mol} \%$ with a just slightly reduced $\mathrm{H}_{2}$-yield of $10.1 \mathrm{wt} \%$. A stoichiometric mixture (46:54 wt \%) of GBH and EDB is theoretically able to deliver 5 equiv of dihydrogen (12.4 wt \%), for which EDB contributes two additional hydrides for the guanidinium cation.

Thus, each protic hydrogen atom has a hydridic counterpart. The experiment yielded a slightly reduced amount of hydrogen $(9.6 \mathrm{wt} \%$ ) with an ammonia impurity of $0.069 \mathrm{~mol} \%$. As ammonia is problematic for fuel-cells the combination of $\mathrm{GBH}$ and EDB depicts an interesting hydrogen storage material. ${ }^{[12]}$ One of the drawbacks of this material is the solid state under standard conditions, which renders it impractical.

Rieger and co-workers modified the cation of GBH by introducing one $\mathrm{N}$-methyl group, which decreases the weight-efficiency of the material, but improves the usability of Me-GBH greatly for homogeneous catalysis (Figure 2). ${ }^{[13]}$ As the methylation lowers the cation's symmetry and, consequently, lowers the melting point, this salt

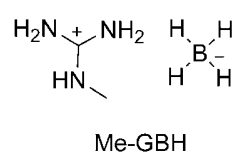

Figure 2.

Structure of Me-GBH. 
remains liquid under standard conditions. ${ }^{[14]}$ This detail makes Me-GBH the first room temperature ionic liquid (RT-IL) employed as efficient hydrogen-source. Initial attempts using an IL containing a cyclohexyl moiety as hydrogen carrier were reported by Dupont and co-workers. ${ }^{[15]}$ The theoretical capacity of Me-GBH of $9.0 \mathrm{wt} \%$ is substantially below that of the wellexplored $A B(19.6 \mathrm{wt} \%) .{ }^{[13]}$ However, the liquid state of Me$\mathrm{GBH}$ under standard-conditions makes this material interesting for future applications and worth investigating further. Furthermore, Me-GBH is superior to dimethylamine borane, which has a hydrogen storage capacity below $4 \mathrm{wt} \%{ }^{[3]}$

Subsequent kinetic studies by Rieger and co-workers showed that dihydrogen-evolution solely by thermal decomposition $\left(75^{\circ} \mathrm{C}\right)$ is too slow and inefficient for application. The authors reported around $9 \mathrm{wt} \%$ hydrogen yield determined by TGA and volumetric quantification for the above mentioned Me-GBH. However, solid state NMR analysis of the residue after dehydrogenation still showed significant amounts of $\mathrm{BH}_{4}{ }^{-}$-species. Experiments employing Wilkinson's catalyst for the decomposition reaction showed considerable improvement in both reaction kinetics as well as overall efficiency. The analysis of the reaction products showed that the catalyzed decomposition results in defined products instead of a polymeric or oligomeric mixture of $\mathrm{B}-\mathrm{N}$-containing species obtained by other attempts. ${ }^{[9,16]}$ Rieger and co-workers proposed dimeric and trimeric boron-bridged guanidinium compounds as by-products based on ESI-MS analysis and theoretical calculations. In general, defined products are important for an efficient regeneration-process. ${ }^{[16]}$ Regarding the regeneration of spent fuel Sutton and co-workers have recently presented meaningful results. ${ }^{[17]}$ The solution of spent fuel in liquid ammonia could be quantitatively reduced by hydrazine to yield $A B$, with gaseous nitrogen as the only by-product.

Employing a metal complex as catalyst is one option to adjust reaction kinetics and optimize low temperature application for the demands of hydrogen-storage materials for transportation applications..$^{[9,18]}$ Another interesting option is the employment of an ionic liquid (IL) as the promoting solvent to support the dehydrogenation of $\mathrm{B}-\mathrm{N}$ frameworks. ${ }^{[11]}$ Sneddon and co-workers showed that application of 1-butyl-3-methylimidazolium chloride $([\mathrm{BMIM}] \mathrm{Cl})$ results in enhanced kinetics $\left(85-95^{\circ} \mathrm{C}\right)$ and improved hydrogen yield albeit with reduced weight efficiency. Another advantage is suppression of the formation of the volatile and undesirable by-product borazine. In more recent research by Sneddon and co-workers reported that various ILs, loaded with different precious metals ( $R h, R u$, $\mathrm{Pd}$ ) or Ni-based pre-catalysts, decreased the onset temperature $\left(45-85^{\circ} \mathrm{C}\right)$ of the decomposition significantly, while improving hydrogen yield. ${ }^{[10]}$ Recent work by Baker and co-workers combined these ideas. ${ }^{[8]}$ In their work, a metal catalyzed dehydrogenation reaction at $60^{\circ} \mathrm{C}$ of a mixture of $A B$ and sec-butylamine borane in the IL 1-ethyl-3-methylimidazolium ethylsulfate ([EMIM][EtSO $]$ ) leaves only a solution of products behind, though the purity of the released hydrogen is not yet proven and efficiency losses attributed to the additional weight are disadvantageous.
In summary these attempts aim at the direction of realizing a liquid hydrogen storage material able to satisfy the requirements of application in mobile devices. After Lentz investigated mixtures of $\mathrm{HzB}$ with $\mathrm{LiH}$, Groshens showed that mixtures of $\mathrm{GBH}$ and $\mathrm{EDB}$ are promising, owing to their efficiency and stability. Rieger showed that it is possible to produce liquid-hydrogen carriers based on GBH capable of releasing dihydrogen efficiently and with tunable properties. Consequentially, Sneddon and Baker catalytically dehydrogenated amine boranes in ILs producing soluble products. More likely the combination of the efficiency of the substrates used by Rieger will be combined with the improvements in applicability achieved by Sneddon and Baker. These recent results in the field of molecular hydrogen storage materials promise even more significant results shortly.

\section{Acknowledgements}

We acknowledge the Ministerium für Innovation, Wissenschaft und Forschung NRW (MIWF-NRW) for financial support within the Energy Research Program for the Scientist Returnee Award for M. H. G. Prechtl (NRW-Rückkehrerprogramm). S. Sahler thanks M. Kessler for helpful discussions.

Keywords: ammonia - borane - homogeneous catalysis hydrogen storage $\cdot$ ionic liquids

[1] C. W. Hamilton, R. T. Baker, A. Staubitz, I. Manners, Chem. Soc. Rev. 2009, 38, 279-293.

[2] L. Schlapbach, A. Zuttel, Nature 2001, 414, 353-358.

[3] A. Staubitz, A. P. M. Robertson, I. Manners, Chem. Rev. 2010, 110, 40794124; M. Felderhoff, C. Weidenthaler, R. von Helmolt, U. Eberle, Phys. Chem. Chem. Phys. 2007, 9, 2643-2653; U. Eberle, M. Felderhoff, F. Schueth, Angew. Chem. 2009, 121, 6732-6757; Angew. Chem. Int. Ed. 2009, 48, 6608-6630; T. B. Marder, Angew. Chem. 2007, 119, $8262-$ 8264; Angew. Chem. Int. Ed. 2007, 46, 8116-8118.

[4] F. H. Stephens, R. T. Baker, M. H. Matus, D. J. Grant, D. A. Dixon, Angew. Chem. 2007, 119, 760-763; Angew. Chem. Int. Ed. 2007, 46, 746-749; B. Loges, A. Boddien, H. Junge, M. Beller, Angew. Chem. 2008, 120, 40264029; Angew. Chem. Int. Ed. 2008, 47, 3962-3965; C. Fellay, P. J. Dyson, G. Laurenczy, Angew. Chem. 2008, 120, 4030-4032; Angew. Chem. Int. Ed. 2008, 47, 3966-3968; J.D. Scholten, M. H. G. Prechtl, J. Dupont, ChemCatChem 2010, 2, 1265-1270.

[5] J. Dupont, P. A. Z. Suarez, Phys. Chem. Chem. Phys. 2006, 8, 2441-2452.

[6] T. J. Groshens, R. A. Hollins, Chem. Commun. 2009, 3089-3091.

[7] T. Hugle, M. F. Kuhnel, D. Lentz, J. Am. Chem. Soc. 2009, 131, $7444-$ 7446.

[8] S. S. Mal, F. H. Stephens, R. T. Baker, Chem. Commun. 2011, 47, $2922-$ 2924.

[9] C. A. Jaska, K. Temple, A. J. Lough, I. Manners, J. Am. Chem. Soc. 2003, $125,9424-9434$.

[10] W. R. H. Wright, E. R. Berkeley, L. R. Alden, R. T. Baker, L. G. Sneddon, Chem. Commun. 2011, 47, 3177-3179.

[11] M. E. Bluhm, M. G. Bradley, R. Butterick, U. Kusari, L. G. Sneddon, J. Am Chem. Soc. 2006, 128, 7748-7749; D. W. Himmelberger, L. R. Alden, M. E. Bluhm, L. G. Sneddon, Inorg. Chem. 2009, 48, 9883-9889.

[12] R. Halseid, P. J. S. Vie, R. Tunold, J. Power Sources 2006, 154, 343-350.

[13] A. Doroodian, J. E. Dengler, A. Genest, N. Rosch, B. Rieger, Angew. Chem. 2010, 122, 1915-1917; Angew. Chem. Int. Ed. 2010, 49, $1871-1873$.

[14] N. M. M. Mateus, L. C. Branco, N. M. T. Lourenco, C. A. M. Afonso, Green Chem. 2003, 5, 347-352.

[15] M. P. Stracke, G. Ebeling, R. Cataluna, J. Dupont, Energy Fuels 2007, 21 , $1695-1698$ 
[16] B. L. Davis, D. A. Dixon, E. B. Garner, J. C. Gordon, M. H. Matus, B. Scott, F. H. Stephens, Angew. Chem. 2009, 121, 6944-6948; Angew. Chem. Int. Ed. 2009, 48, 6812-6816.

[17] A. D. Sutton, A. K. Burrell, D. A. Dixon, E. B. Garner, J. C. Gordon, T. Nakagawa, K. C. Ott, P. Robinson, M. Vasiliu, Science 2011, 331, 1426-1429.
[18] G. Alcaraz, S. Sabo-Etienne, Angew. Chem. 2010, 122, 7326-7335; Angew. Chem. Int. Ed. 2010, 49, 7170-7179.

Received: March 28, 2011

Published online on July 8, 2011 